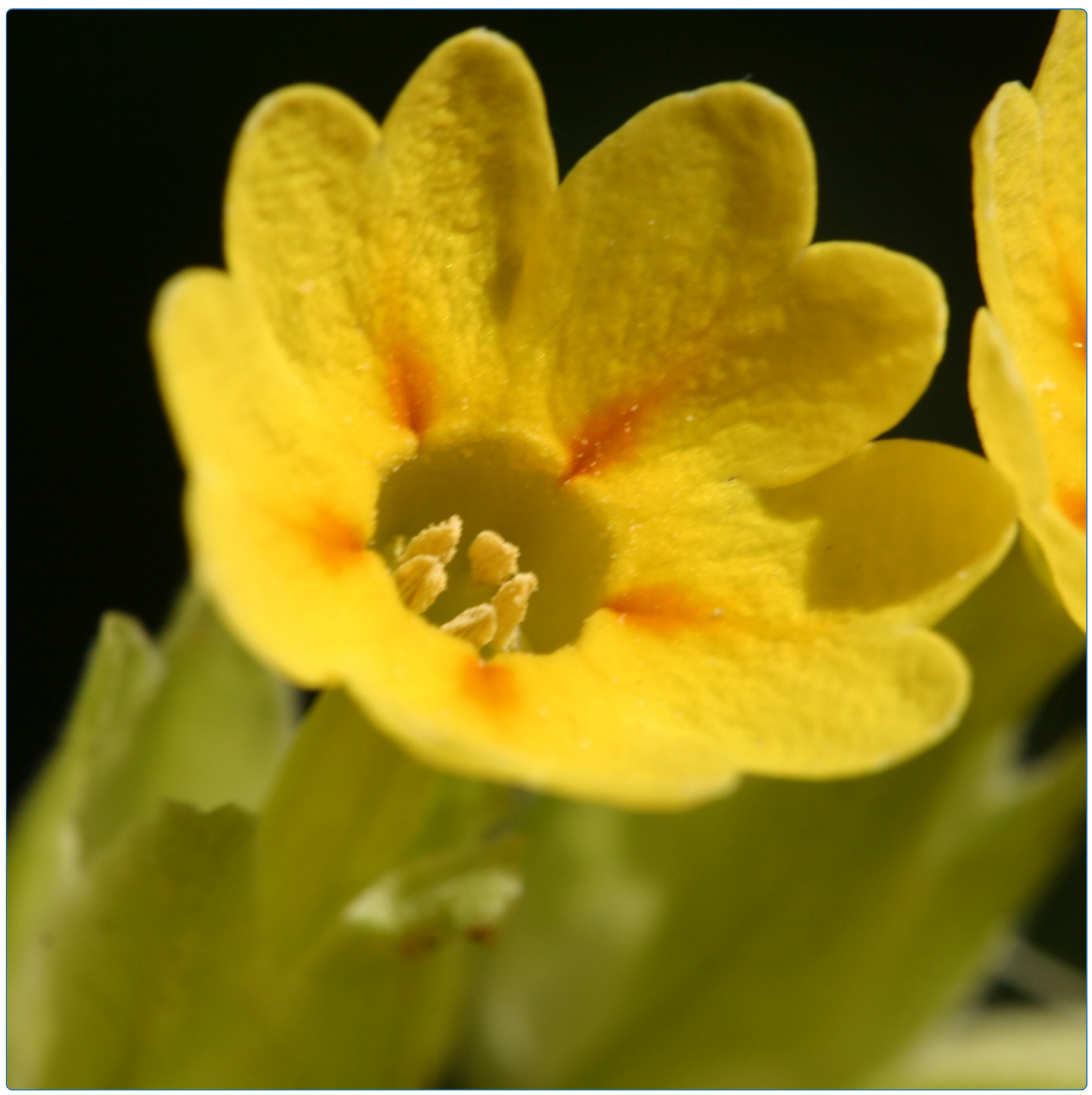

The draft genome of Primula veris yields insights into the molecular basis of heterostyly

Nowak et al. 


\title{
The draft genome of Primula veris yields insights into the molecular basis of heterostyly
}

\author{
Michael D Nowak ${ }^{1,2^{*}}$, Giancarlo Russo ${ }^{3}$, Ralph Schlapbach ${ }^{3}$, Cuong Nguyen Huu ${ }^{4}$, Michael Lenhard ${ }^{4}$ and Elena Conti ${ }^{1}$
}

\begin{abstract}
Background: The flowering plant Primula veris is a common spring blooming perennial that is widely cultivated throughout Europe. This species is an established model system in the study of the genetics, evolution, and ecology of heterostylous floral polymorphisms. Despite the long history of research focused on this and related species, the continued development of this system has been restricted due the absence of genomic and transcriptomic resources.

Results: We present here a de novo draft genome assembly of $P$. veris covering $301.8 \mathrm{Mb}$, or approximately $63 \%$ of the estimated $479.22 \mathrm{Mb}$ genome, with an N50 contig size of $9.5 \mathrm{~Kb}$, an N50 scaffold size of $164 \mathrm{~Kb}$, and containing an estimated 19,507 genes. The results of a RADseq bulk segregant analysis allow for the confident identification of four genome scaffolds that are linked to the P. veris S-locus. RNAseq data from both $P$. veris and the closely related species $P$. vulgaris allow for the characterization of 113 candidate heterostyly genes that show significant floral morph-specific differential expression. One candidate gene of particular interest is a duplicated GLOBOSA homolog that may be unique to Primula (PveGLO2), and is completely silenced in L-morph flowers.
\end{abstract}

Conclusions: The $P$. veris genome represents the first genome assembled from a heterostylous species, and thus provides an immensely important resource for future studies focused on the evolution and genetic dissection of heterostyly. As the first genome assembled from the Primulaceae, the P. veris genome will also facilitate the expanded application of phylogenomic methods in this diverse family and the eudicots as a whole.

\section{Background}

With over 350,000 described species, angiosperms currently represent the dominant, most diverse group of plants on earth [1]. Their success has been frequently linked with the evolution of a complex structure, the flower, which typically includes both male and female sexual organs - often inconspicuous - inside whorls of attractive, asexual organs. This evolutionary innovation opened up a new landscape of opportunities for elaborate interactions with animals, mostly insects, which can transfer male gametes (that is, pollen grains) between flowers of different plants more efficiently than abiotic vectors (for example, wind; [2,3]). Most flowers are hermaphroditic, theoretically enabling fertilization within the same individual (selfing), a breeding system that

\footnotetext{
* Correspondence: michaeldnowak@gmail.com

'Institute of Systematic Botany, University of Zürich, Zollikerstrasse 107, 8008

Zürich, Switzerland

${ }^{2}$ Natural History Museum, University of Oslo, P.O. Box 1172, Blindern

NO-0318, Oslo, Norway

Full list of author information is available at the end of the article
}

can lead to detrimental evolutionary consequences $[4,5]$. Different strategies have thus evolved in flowering plants to avoid selfing and promote outcrossing, and one of the most effective mechanisms is heterostyly.

Extensively investigated in primroses (Primula L., Primulaceae) by Darwin [6], heterostyly refers to a floral polymorphism whereby individuals in a population produce dissimilar types of flowers (two in some taxa, three in others) with male and female sexual organs in different, but spatially matching positions [7]. For example, in Primula, plants produce two types of flowers (that is, distyly): either long-styled flowers with anthers attached midway along the floral tube ('L-morph', or 'pin'), or short-styled flowers with anthers attached at the top of the floral tube ('S-morph', or 'thrum'). Male and female sexual organs of L-morph and S-morph flowers, respectively, are thus placed in complementary positions, a condition known as reciprocal herkogamy. Heterostylous species frequently employ a genetic mechanism for rejecting pollen of the same plant and pollen from the same floral morph known as 
heteromorphic self-incompatibility [8]. The combination of reciprocal herkogamy and self-incompatibility enforces outcrossing $[9,10]$, thus avoiding the potentially negative effects of inbreeding. The adaptive value of heterostyly may thus explain why this system has evolved repeatedly in the angiosperms, and is presently known to occur in at least 28 different families [11].

The best-studied group of heterostylous plants is arguably Primula, comprising 400 to 500 species, of which approximately $90 \%$ are distylous and $10 \%$ homostylous, the latter producing self-compatible flowers of only one type. Primroses occur primarily in temperate, alpine, and arctic habitats of the northern hemisphere, with the main center of species diversity in the Sino-Himalayan region and secondary centers in the major, circumboreal mountain chains [12]. Owing to its fascinating reproductive system, attractive flowers, and common occurrence in the historical centers of Western science, the genus has been intensively examined from comparative perspectives for at least 150 years. Numerous studies are thus available on phylogenetic relationships within the genus (for example, $[13,14]$ ), biogeography, ecology, and variation of ploidy levels (for example, [15-19]), floral and reproductive biology (for example, [6,9,10,20,21]), genetics of heterostyly (for example, [22-25]), evolution of breeding systems (13, for example, [26-28]), and conservation ecology and genetics (for example, [29,30]). Furthermore, primroses also represent one of the most popular garden plants in Europe, Japan, and North America, valued as spring-blooming perennials and rock-garden alpines. Primroses are prominent in the horticultural trade, and business associated with the sale of plants, organization of exhibitions, and collecting expeditions is estimated at 50 million USD annually (J. Richards, personal communication).

Within the genus, Primula section Primula has received the most scientific attention, starting with Darwin's [6] seminal work on the floral morphology and reproductive biology of Primula veris (cowslip), Primula vulgaris (primrose), and Primula elatior (oxlip). The section includes six distylous and one homostylous species, all diploids with a base chromosome number of 11 (that is, $2 n=2 x=$ 22). Typical elements of the spring flora in many parts of Eurasia, these three species are the most widespread in the section, ranging from Western Europe to central and even far-Eastern Asia [31]. Their abundance and easy accessibility in Europe may partially explain why they have been investigated so intensively. A broad range of studies have been performed on reproductive isolation and hybridization among these three species $([9,10]$, for example, [32-41]), pollination biology, ecology and conservation (for example, [42-46]), floral morphology, self-incompatibility, and the genetics of distyly (for example, [47-52]).
The genus, and in particular Primula sect. Primula, have thus emerged as a model for a broad spectrum of evolutionary, ecological, and conservation studies, and as the paradigm for exploring the genetic control of distyly $[7,53]$. Classic genetic studies on primroses, based on manual crosses and segregation analyses, established that distyly is governed by a single Mendelian locus (the $S$-locus), with long-styled and short-styled plants being homozygous (ss) and heterozygous (Ss), respectively, and the homozygous dominant genotype $(S S)$ being lethal [54-57]. A minimum of three genes are thought to be tightly linked at the $S$-locus (sometimes called the S-supergene), controlling the length of the style ( $G g$ : short; gg: long), the position of the anthers (Aa: high; $a a$ : low), the size of pollen grains ( $P p$ : large; $p p$ : small) and other ancillary traits ([23], for example, the length of the stigmatic papillae $[24,58,59])$. Large populations often harbor individuals with intermediate phenotypes suggestive of rare recombination events at the $S$-locus. Lewis and Jones [23] used the frequency of such recombinants to infer the linkage order of the three loci as GPA in Primula subgenus Auriculastrum, but Kurian and Richards [24] found that the gene order was more likely GAP in Primula section Primula. Beyond the relative order of the three linked loci, little is known regarding the absolute size of the Primula S-locus, as well as the number and function of specific genes that these loci represent [8]. To date, just three genes have been identified as potentially linked to the Primula S-locus, and none of these have been proposed as functionally integral to the differential development of L- and S-morph flowers. In 2007, Li et al. [60] employed fluorescent differential display to identify, clone, and sequence L- and S-morph alleles of two genes that they named PvSLL1 and PvSLL2, which represent an unknown plasma membrane protein, and a gene with sequence similarity to Arabidopsis flower-timing genes Col9 and Col10, respectively. While searching for the genes responsible for the $S$-locus-linked floral homeotic mutant sepaloid in Primula vulgaris, Li et al. [60] identified $P v G L O$, a homolog to the B-function MADS-box gene GLOBOSA. While their results suggested that $P \nu G L O$ was not likely responsible for the mutant sepaloid phenotype, the gene appeared to carry alleles exhibiting morphspecific segregation, and it was thus assumed to be linked to the Primula $S$-locus.

Given that the Primula $S$-locus is largely shielded from recombination, there are certain well-established theoretical predictions that can be made regarding the genome sequence harboring the $S$-locus. The classic model of Muller's Ratchet predicts that reduced recombination will lead to the fixation of a large number of linked sites on both L-morph and S-morph S-locus haplotypes [61]. This implies that both coding and non-coding sequence residing within the boundaries of the $S$-locus should 
exhibit elevated heterozygosity in S-morph $(S s)$ plants relative to L-morph plants (ss).

Despite the plethora of evolutionary, ecological, morphological, and genetic studies on Primula and its longstanding value as a prime biological study system, we still lack the genomic resources that would allow us to perform detailed analyses of speciation processes, identify areas of the genome that are more porous to introgression, characterize the genetic basis of adaptation to alpine/arctic habitats, exploit the genes that control traits of special horticultural value, and finally elucidate the enduring mystery of the molecular basis of distyly. In turn, the molecular characterization of the $S$-locus would open up new avenues of research into the evolutionary pathways leading to heterostyly $[27,62,63]$ and the repeated evolution and loss of this trait in angiosperms $[14,28,64]$. Here, we present the first draft genome assembly of a heterostylous species, focusing on Primula veris, because this species has long been a favorite target of scientific studies (as reviewed above) and represents a well-defined evolutionary lineage [31]. This species is diploid with a chromosome number of $2 n=22$ and estimated DNA content of 479.22 Mb [65]. Our aim in assembling the $P$. veris genome is primarily to develop genomic resources for this species and the entire genus Primula, to identify genome scaffolds that segregate with the $P$. veris $S$-locus, and to use these newly created resources to examine genes previously identified as linked to the Primula $S$-locus and characterize novel candidate distyly genes. Our genome and transcriptome assemblies enable the continued development of $P$. veris as a model system to study the genetic components of the $S$-locus and the evolution and maintenance of reproductive barriers within Primula sect. Primula.

\section{Results and discussion}

\section{Genome and transcriptome assemblies}

We generated a large amount of sequence data from a diverse suite of sequencing libraries to assemble the draft $P$. veris genome. A full account of our sequencing efforts is shown in Table 1. Using these data, we employed a twostep strategy for de novo genome assembly in order to fully leverage the long-read data generated by PacBio RS. Our first assembly was performed using only short-read (that is, 100 to $250 \mathrm{bp}$ ) sequences generated from standard paired-end and 3 to $9 \mathrm{~Kb}$ mate-pair libraries on Illumina HiSeq, MiSeq, and Ion Proton platforms. This assembly was based on a total of $54.5 \mathrm{~Gb}$ of raw data and resulted in a total of 48,812 contigs that were grouped into 9,002 unique scaffolds (Additional file 1: Table S1). The total contig length is $232.2 \mathrm{Mb}$ and the total scaffold length, including gaps, is $301.8 \mathrm{Mb}$, which represent $49 \%$ and $63 \%$, respectively, of the estimated $479.22 \mathrm{Mb} P$. veris genome [65]. The N50 contig size is $9.5 \mathrm{~Kb}$, and the N50 scaffold size including gaps is $164 \mathrm{~Kb}$, with a median gap size of $960 \mathrm{bp}$. The largest and smallest scaffolds are $2.14 \mathrm{Mb}$ and 888 bp, respectively.

The transcriptome sequencing of $P$. veris and $P$. vulgaris yielded more than 200 million paired reads, which were distributed quite evenly among the six RNAseq libraries that we multiplexed and sequenced in parallel on a single Illumina flow cell (Additional file 1: Table S2). Our de novo $P$. veris transcriptome assembly contains 25,409 putatively unique transcripts, and the $P$. vulgaris transcriptome assembly contains 24,318 unique transcripts. We also performed de novo transcriptome assemblies of the related species $P$. obconica, $P$. wilsonii, and $P$. poissonii using data available on the Genbank Sequence Read Archive (SRA). Our de novo transcriptome assembly of

Table 1 Summary of sequence data used in the de novo assembly of the draft $P$. veris genome

\begin{tabular}{|c|c|c|c|c|c|c|}
\hline Library type & Platform & Reads & Bases & Coverage $^{a}$ & Insert size ${ }^{a}(b p)$ & Read length $^{\mathrm{a}}(\mathrm{bp})$ \\
\hline Standard paired-end & Illumina HiSeq & $222,499,994$ & $22,249,999,400$ & 50 & 180 & 100 \\
\hline \multirow[t]{3}{*}{ Mate pair (small) } & Illumina HiSeq & $59,854,090$ & $5,985,409,000$ & 15 & 3,298 & 100 \\
\hline & Illumina MiSeq & $109,369,174$ & $8,340,785,860$ & 19 & 3,348 & 76 \\
\hline & Ion Proton & $35,503,706$ & $1,584,426,676$ & 4 & 3,412 & 44 \\
\hline Total & & $204,726,970$ & $15,910,621,536$ & 38 & & \\
\hline \multirow[t]{2}{*}{ Mate pair (medium) } & Illumina HiSeq & $37,705,200$ & $3,770,520,000$ & 9 & 6,048 & 100 \\
\hline & Illumina MiSeq & $43,084,090$ & $3,590,695,375$ & 8 & 6,084 & 83 \\
\hline Total & & $80,789,290$ & $7,361,215,375$ & 17 & & \\
\hline \multirow[t]{2}{*}{ Mate pair (large) } & Illumina HiSeq & $55,721,478$ & $5,572,147,800$ & 13 & 8,900 & 100 \\
\hline & Illumina MiSeq & $42,153,704$ & $3,425,486,254$ & 8 & 8,938 & 81 \\
\hline Total & & $97,875,182$ & $8,997,634,054$ & 21 & & \\
\hline Total (short-read data) & & & $32,269,470,965$ & 116 & & \\
\hline Long read fragment $10 \mathrm{~kb}$ & PacBio RS & $2,357,643$ & $3,437,918,089$ & 7 & NA & $3,658^{\mathrm{b}}$ \\
\hline
\end{tabular}

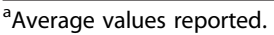

${ }^{\mathrm{b}}$ See also Additional file 2: Figure S1. 
P. obconica was found to contain 22,752 transcripts, but the transcriptome assemblies of $P$. poissonii and $P$. wilsonii were considerably smaller, with 11,905 and 12,927 unique transcripts, respectively. This reduced transcript pool likely represents the fact that the publicly available Genbank SRA data for these species contained far fewer raw sequence reads [66] than those we produced for $P$. veris and $P$. vulgaris, and than the reads available in the SRA for P. obconica.

To improve our $P$. veris genome assembly, we generated 3.4 Gb of PacBio RS sequence data with an average read length of 3,658 and an average base quality of 0.834 (Additional file 2: Figure S1). These data, which contribute an additional $8 \times$ coverage for the $P$. veris genome, were integrated into our assembly through the implementation of the PbJelly software tool [67]. The PBJelly algorithm essentially anchors the long PacBio reads to the existing contigs and scaffolds and extends them partially spanning the contiguous gaps. When PacBio sequences are long enough to be anchored to both sides of a gap, then the gap is fully closed. Adding the PacBio RS data to the assembly resulted in a total of $21.15 \%$ of the gaps in the previous assembly being entirely closed and $38.4 \%$ of the ambiguous positions in the gaps being filled. This translated into a significant improvement of both the compactness and completeness of our de novo $P$. veris genome. At 269.7 Mb, the new total contig length increased by $19.4 \%$; the new total scaffold length (including gaps) reached $310.07 \mathrm{Mb}$, a $2.7 \%$ increase over the draft assembly based on the Illumina and Ion Proton data alone. In terms of genome completeness, these contiglength numbers represent $56.3 \%$ and $64.7 \%$, respectively, of the $P$. veris genome. The updated draft is also more compact: the number of contigs was reduced, by $16.88 \%$, to 40,569 contigs, grouped into 8,764 unique scaffolds (2.65\% fewer scaffolds, see Additional file 1: Table S1). At $13.3 \mathrm{~Kb}$, the N50 contig size grew by $40 \%$, whereas the N50 scaffold size including gaps reached $165.9 \mathrm{~Kb}$, with a median gap size of $664 \mathrm{bp}$. The largest and smallest contigs are 233,407 bp and $19 \mathrm{bp}$, respectively. The sizes of the largest and smallest scaffolds remained $2.14 \mathrm{Mb}$ and 888 bp, respectively; this is not surprising, since gapclosing tends to bridge scaffolds of low to medium size. The assembly scaffolds on average contain 29 ambiguities per $10 \mathrm{~kb}$. The GC content of the scaffolds, excluding gaps, is $33 \%$, which is similar to the genome sequences of tomato (34\%; [68]) and kiwifruit (35.2\%; [69]).

Although the success of a draft genome assembly is strongly dependent on the genetic complexity of the specific organism and its genome size, we find the overall quality of the draft $P$. veris assembly, based on the aforementioned measures, to be consistent with the majority of de novo genome assembly efforts reported in the last few years. Unsurprisingly, genome assemblies generated from highly homozygous samples, such as the PN40024 grapevine line [70], or those employing a larger number of ad hoc mate pair libraries (for example, domesticated apple Malus $\times$ domestica [71]; kiwifruit Actinidia chinensis [69]; mulberry Morus notabilis [72]) resulted in higher quality drafts exhibiting a three- to four-fold decrease in the number of scaffolds and a two- to four-fold increase in the corresponding N50, relative to our assembly. However, when compared to assemblies in which similar resources were used, our assembly is quite compact. For example, our $P$. veris assembly is between two and 10 times more compact than the draft genomes of Cannabis sativa [73] and European pear (Pyrus communis 'Bartlett' [74]), which contain 136,290 and 142,083 scaffolds, respectively, and scaffold N50s smaller than $90 \mathrm{~Kb}$. These genome projects employed two mate pair libraries of sizes similar to our study, but it is important to point out that their minimum contig size was less than 500 bp, while our assembly is based on a minimum contig size of 1,000 bp. Our assembly is one of the first to specifically employ PacBio sequence data to fill scaffold gaps in a heterozygous plant genome, and this aspect, together with the use of a third, larger mate pair library, may be responsible for the improved compactness (that is, fewer contigs) of our assembly.

\section{Genome annotation and quality assessment}

Of the 8,764 scaffolds that make up our genome assembly, $2,495(28.5 \%)$ were found to contain annotated genes. Our final annotation of the $P$. veris genome contained a total of 19,507 predicted genes, less than the number of genes found in the relatively well-annotated genomes of Arabidopsis thaliana (27,029 genes; [75]), sacred lotus (Nelumbo nucifera, 26,685 genes; [76]), and mulberry (29,338 genes; [72]). Furthermore, we find about 7,000 fewer genes predicted in the genome annotation compared with the de novo $P$. veris transcriptome assembly (25,409 predicted genes; see above), but most likely the real number of genes is somewhere in between those two estimates, and a combination of factors might have contributed to underestimating the predictions in the genome annotation and inflating the number of genes predicted in the de novo transcriptome assembly. First, transcripts predicted by the de novo transcriptome assembly are based on only one source of evidence, that is, the RNA-seq data, and represent only one source of evidence in the Maker2 genome annotation process. For a transcript to be reported by Maker2, at least two sources of evidence are required, hence those transcripts that are not strongly supported by a second source of evidence, such as $a b$ initio gene prediction algorithms or protein homology are not reported in the final genome annotation. Additionally, a de novo transcriptome assembly alone is often not able to completely discriminate between multiple isoforms of a specific gene, 
which may slightly inflate the estimated number of genes based on these data alone. The predicted gene content of $P$. veris is significantly reduced compared to kiwifruit (39,040 genes [69]) and European pear (43,413 genes [74]), probably owing to the relatively recent whole genome duplications in the latter two species. The Maker2 pipeline identified a total of 279,271 repetitive elements representing approximately $7 \%$ of the $P$. veris draft genome assembly (Additional file 1: Table S3).

To assess the completeness of the final genome assembly, we searched for the presence of 248 conserved core eukaryotic genes using the CEGMA software package (CEGs; [77]). We found confident hits to 198 (79.84\%) full length (that is, $>70 \%$ alignment) CEG proteins and 234 partial (94.35\%) CEG proteins, where partial matches are defined by the CEGMA default pre-computed minimum alignment score for each CEG [77]. These results suggest an exceptional level of completeness for this first draft genome sequence of a heterozygous, non-model plant. Annotated scaffolds contained a median number of four genes, and the largest scaffold (Contig0; $2.15 \mathrm{Mb}$ ) was found to contain 352 predicted genes, and generally, longer scaffolds tend to contain more genes. The quality of the gene prediction and annotation was evaluated in a number of ways. Searching the predicted gene set with the InterProScan tool, we found that $15,659(85.6 \%)$ of predicted proteins contain PFAM domains. One commonly applied quality metric of genome annotations is the cumulative annotation edit distance (AED), which represents the agreement between predicted gene models and external evidence. A gene model with an AED score of zero indicates complete agreement between the predicted gene model and, for example, a transcript from the de novo $P$. veris transcriptome assembly, which we incorporate as external evidence in the Maker2 pipeline [78]. As the $a b$ initio gene predictors are trained through iterative Maker2 runs, the cumulative fraction of predicted gene models with low AED scores increases, thus indicating more agreement between gene models and external evidence (Additional file 3: Figure S2). In our final annotation, approximately $80 \%$ of gene models have an AED score of 0.2 or less, indicative of a high degree of agreement between predicted gene models and external evidence.

\section{Comparative transcriptome analyses}

We used the OrthoMCL pipeline $[79,80]$ to identify sets of putatively orthologous loci at two phylogenetic scales:

(1) among transcriptomes of five species of Primula; and (2) among $P$. veris and four Euasteridae species with published genome assemblies (Figure 1). Our comparative Primula transcriptome analyses confidently identified a total of 4,207 orthologs among the transcriptomes of $P$. veris, $P$. vulgaris, $P$. obconica, $P$. wilsonii, and $P$. poissonii, with 2,391 of these likely representing single-copy genes in all of the species (Figure 1A; see Additional file 4). The most recent phylogenetic hypotheses for the genus Primula suggest that $P$. veris, $P$. vulgaris [31] and P. poissonii, P. wilsonii, respectively, belong to two different sister clades, [66], with P. obconica included in a third clade basal to the other two clades $[13,14]$. Our results are consistent with these hypothesized phylogenetic relationships, for we find more shared orthologs between $P$. vulgaris and $P$. veris than in all other pairwise comparisons $(3,205)$, and a similar number of putatively orthologous genes limited to $P$. veris, $P$. vulgaris, and $P$. obconica $(3,211)$. However, we do not see a similar number of shared orthologs unique to the sister species $P$. poissonii and $P$. wilsonii (487), but this result might be explained by the fact that these transcriptomes were assembled with far less sequence data [66] than our de novo transcriptome assemblies, and thus they are likely to represent a smaller proportion of the expressed genes. Our comparative analyses of euasterid transcriptomes identified a total of 8,079 putatively orthologous genes, and of these approximately 2,402 are likely to be single copy in all examined species (Figure 1B; see Additional file 5). These orthologous gene sets provide a framework for the development of future phylogenomic studies aimed at resolving species-level relationships within the genus Primula, or deeper phylogenetic relationships within the Euasteridae.

\section{Gene expression differences between floral morphs and functional analysis of candidate genes}

To search for genes that might underlie the phenotypic differences between the floral morphs in Primula, we compared gene expression between flowers of L- and S-morph plants in both $P$. vulgaris and $P$. veris. Given that we sampled RNA from floral bud tissues 3 to 5 days prior to anthesis, our results are primarily relevant to the later stage of floral development. At this stage, cell growth in the style and in the corolla tube below the point of stamen attachment differs between L- and S-morph flowers. Differential cell growth is thought to be primarily responsible for differences in style length and the relative position of the anthers in the middle or the top of the corolla tube, respectively [48]. We adopted a BenjaminiHochberg false discovery rate (FDR) at 5\% level to correct for multiple testing. At an FDR-adjusted $P$ value threshold of 0.05 , we found 620 and 677 genes in $P$. veris and $P$. vulgaris, respectively, that exhibited significant differential expression between morphs. To reduce the number of false positives in this gene set, we retained only the 113 genes that exhibit morph-specific differential expression in both $P$. veris and $P$. vulgaris floral buds (Additional file 1: Table S4). Of these 113 genes, the majority (that is, 73 genes) showed increased expression in S-morph versus L-morph floral buds. Because the distylous phenotype is 


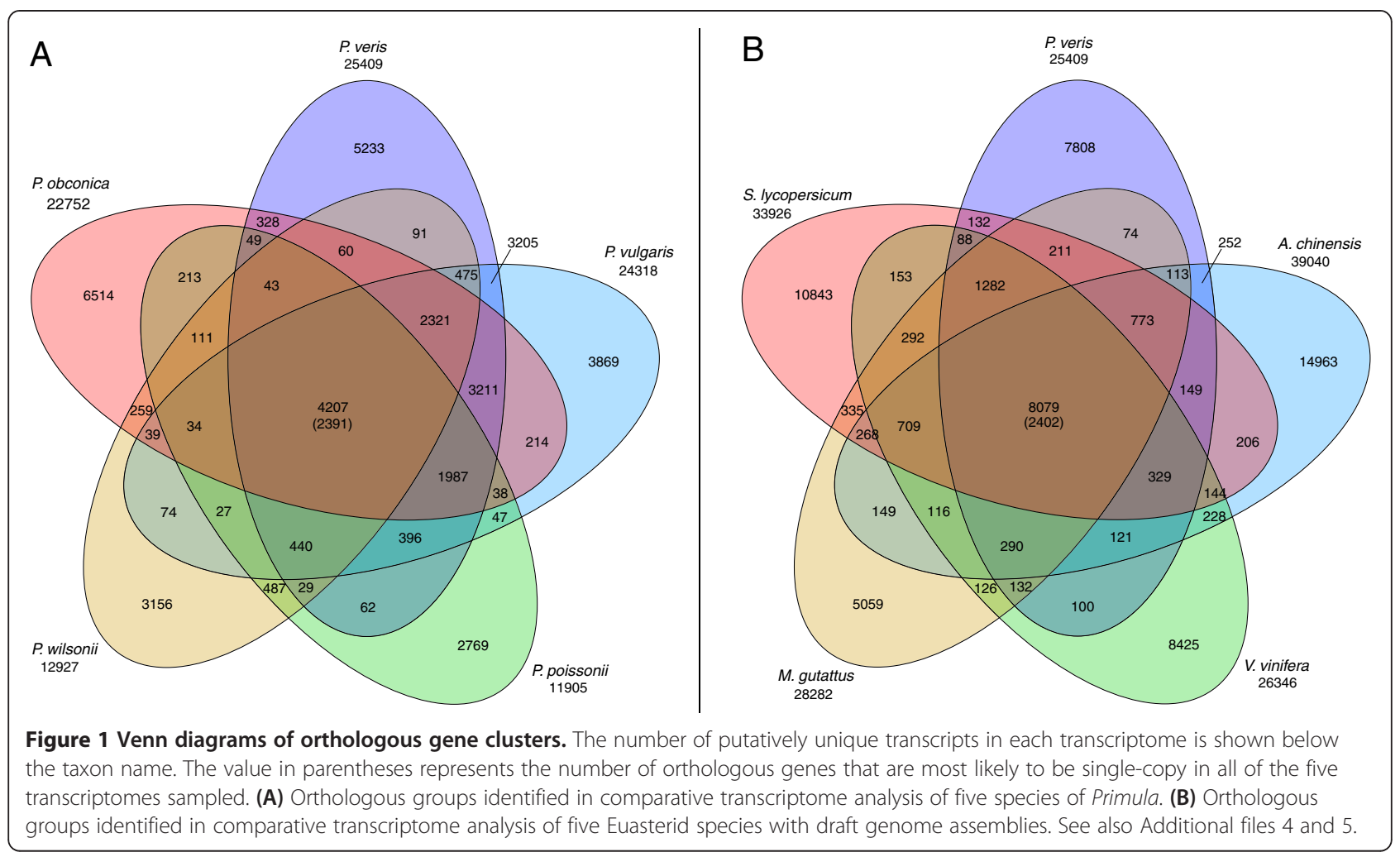

limited to floral tissues, it is likely that genes involved in determining the floral morph would not be differentially expressed in L- and S-morph leaf tissues. We find that, of these 113 genes showing floral morph-specific differential expression, 69 are not differentially expressed in P. veris L- and S-morph leaves (Additional file 1: Table S4).

We examined the candidate set of 113 differentially expressed genes to determine the types of functional gene classes represented. Functional annotations for 92 of the 113 genes were clustered using the DAVID bioinformatics resources, while the remaining 21 genes contained no conserved protein domains and are not readily assignable to functional classes. Annotation clusters represent groups of functionally similar GO terms associated with the gene list, thus providing a more direct biological interpretation of related terms for large gene lists [81]. As seen in Figure 2, GO terms attributed to the 92 genes showing morph-specific differential expression can be grouped into 17 annotation clusters. More than $40 \%$ of the candidate genes involved in differential floral morph expression contain GO terms attributable to annotation cluster 1, which is characterized by the terms 'extracellular', 'secreted', and 'hydrolase', among others (Additional file 1: Table S5). These terms could be related to a wide array of biological processes, but it is plausible that some of the genes might control mechanisms of heteromorphic self-incompatibility typical of distylous Primula species. Self- and intra-morph pollen tube inhibition in Primula is thought to result from biochemical interactions between the pollen grain or pollen tube and tissues of the stigma and/or style $[82,83]$. Such biochemical interactions are likely to occur in the extracellular matrix or at the stigmatic surface, thus requiring the active secretion of molecules involved in the heteromorphic self-incompatibility mechanism [52,84-87].

The remaining 16 annotation clusters contain GO terms associated with $25 \%$ to approximately $3 \%$ of the candidate genes; among these are a few clusters that stand out as being potentially relevant to the phenotypic differences associated with the two floral morphs. Specifically, annotation clusters 2 and 7 are characterized by GO terms associated with cell-wall organization and cell growth, respectively. These clusters are particularly interesting in the context of morph-specific development, because many of the phenotypic differences that define the L- and S-morph flowers involve differential cell proliferation and elongation in the corolla tube (the $A$ gene) and the style (the $G$ gene, $[12,48,88])$. Annotation cluster 15 is characterized by the terms 'post-embryonic development', 'reproductive structure development', and 'reproductive developmental process' (Additional file 1: Table S5). Floral development genes frequently act as transcription factors regulating the expression of a diverse suite of genes that influence the development of specific floral structures [89]. It is thus possible that the genes associated with the GO terms of annotation cluster 15 could be coordinating the developmental changes associated with differential cell elongation 


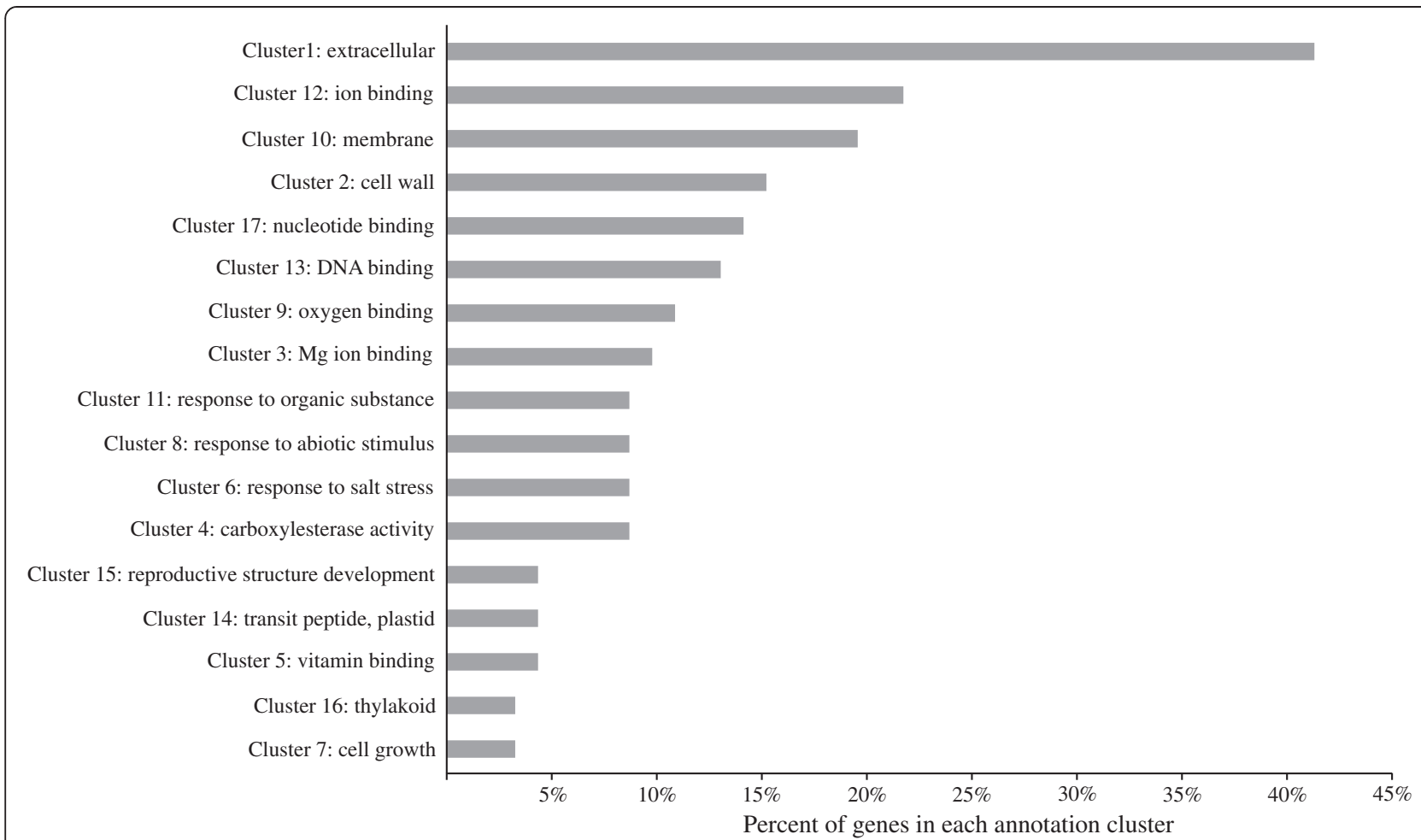

Figure 2 Distribution of genes differentially expressed in L- and S-morph plants assigned to functional annotation clusters. Annotation clusters are labeled with a single GO term that is representative of all of the terms defining cluster membership. See Additional file 1: Table S5 for a complete listing of $\mathrm{GO}$ terms associated with each annotation cluster.

observed in corolla tubes and styles of L- and S-morph plants.

\section{GLO1 \& GLO2: Duplicated GLOBOSA homologs in Primula}

One of the most intriguing results of our differential expression analysis in $P$. veris and $P$. vulgaris is the fact that BG8816696, the gene with the most significant morphspecific differential expression (as measured by FDR-adjusted $P$ value; Additional file 1: Table S4), is strikingly similar to the B-function MADS-box gene GLOBOSA ( $E$-value $=0)$, which is a transcription factor integral in the normal development of petals and stamens in Antirrhinum majus [90]. Blast searches reveal that this gene had been previously sequenced from $P$. vulgaris by Li et al. [60] and from P. denticulata by Viaene et al. [91]. While Li et al. [60] considered this gene to be single copy, Viaene et al. [91] realized that there were actually two GLOBOSA homologs in $P$. denticulata. When we map the GLOBOSA homologs from $P$. vulgaris $\left(P \nu G L O^{P 1}, P \nu G L O^{P 2}\right.$, and $\left.P \nu G L O^{T}\right)$ and P. denticulata ( $P d G L O 1$ and $P d G L O 2$ ) to our genome assembly, we find unequivocal support for two distinct GLOBOSA genes in Primula. Specifically, we find that $\mathrm{Li}$ et al.'s [60] two putative L-morph alleles (named $P v G L O^{P I}$ and $P v G L O^{P 2}$ by the authors) and PdGLO1 [91] map to an entirely different scaffold than the putative S-morph allele $\left(P v G L O^{T}[60]\right)$ and $P d G L O 2$ [91]. We hereby refer to these two genes as PveGLO1 (BG8816827), which is homologous to PdGLO1 and the two alleles $P v G L O^{P 1}$ and $P v G L O^{P 2}$ [60], and PveGLO2 (BG8816696), which is homologous to PdGLO2 and $P v G L O^{T}$ (Figure 3). Viaene et al. [91] failed to find evidence for two GLOBOSA homologs in a monomorphic species of Primulaceae (Cyclamen persicum), and thus it is possible that the duplicated GLOBOSA could be specific to the genus Primula. By comparing the mRNA sequences of $P v G L O^{T}$ [60], PdGLO2 [91], and PveGLO2 assembled from S-morph RNAseq data with the scaffold sequence carrying PveGLO2 (Contig1404), we find that the last exon and 3' UTR appear inverted in the genome assembly. This inversion in the scaffold sequence is likely the product of an assembly error, because the transcriptome assembly contains a complete PveGLO2 gene and there is a large (approximately $10 \mathrm{~Kb}$ ) assembly gap within the last intron of the PveGLO2 gene model. PveGLO2 is completely silenced in L-morph flowers of $P$. veris and $P$. vulgaris, which - in light of Li et al.'s [60] finding of linkage between PveGLO2 (PveGLO ${ }^{T}$ in their terminology) and the S-morph haplotype of the $S$-locus in $P$. vulgaris - could reflect the absence of this gene from the L-morph haplotype. Thus, while we currently do not have evidence for PveGLO2 being linked to the $S$-locus in $P$. veris (see below), this duplicated B-function MADS-box gene is an attractive 


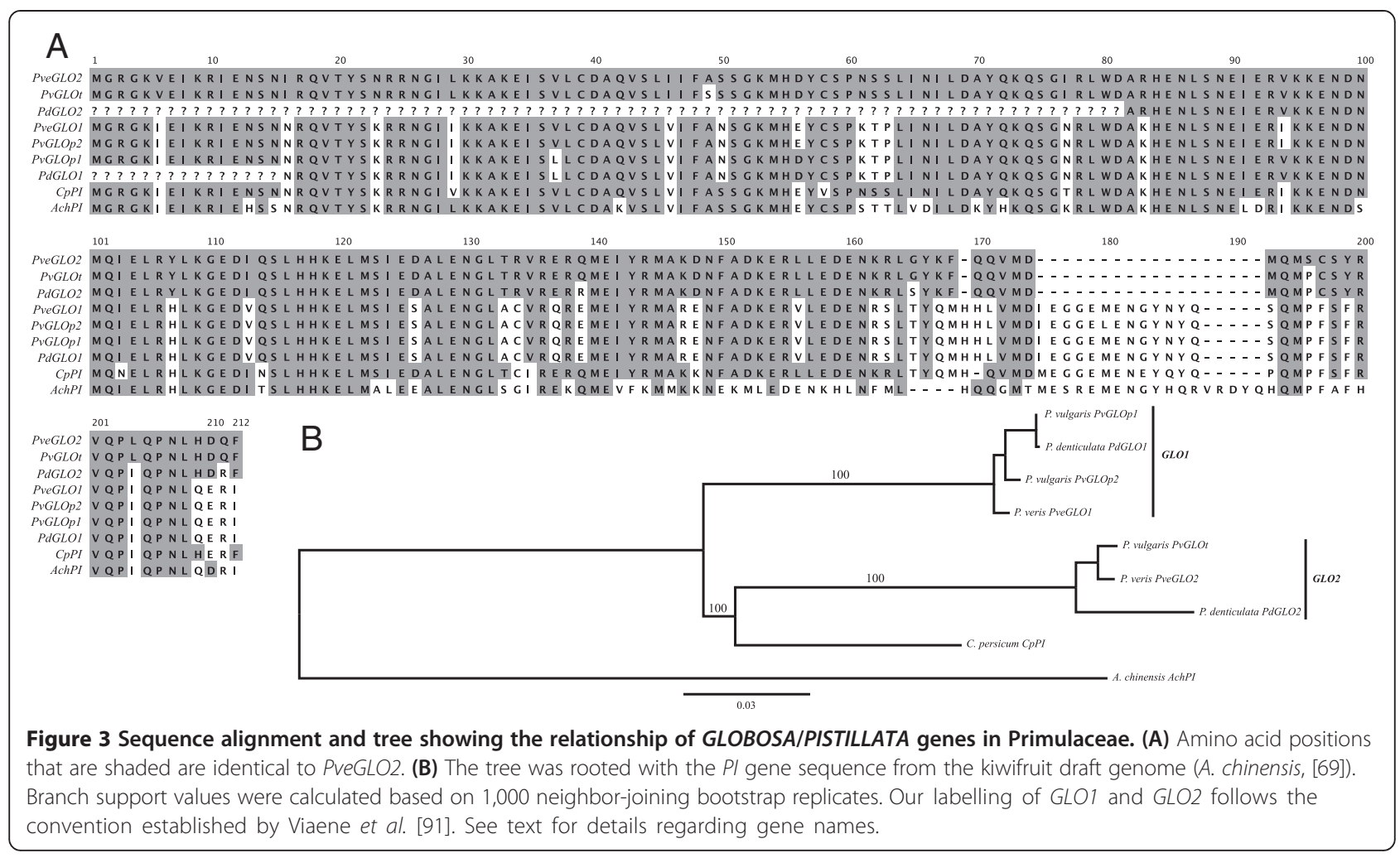

candidate for future studies of distylous flower development in Primula.

\section{Bulk Segregant RAD-Seq identifies SNPs linked to the $P$. veris $S$-locus}

To enable testing of the above hypotheses about properties of $S$-locus linked sequences, we aimed to experimentally identify corresponding scaffolds. To this end, we searched for sequence polymorphisms tightly linked to the $S$-locus in $P$. veris, using a RAD-seq bulk segregant analysis on pooled L-morph and S-morph DNA. Any polymorphisms that are closely linked to the $S$-locus should be largely homozygous in the L-morph pool, but heterozygous in the S-morph pool. Using a stringent set of criteria (coverage in both pools $>60 \times$, allele frequency in L-morph pool 1.0, allele frequency in S-morph pool 0.3-0.7), this analysis identified 24 SNPs as potentially tightly linked to the $S$ locus (see Additional file 6).

To enable high-throughput genotyping, the SNPs identified above were converted to PCR-based markers, either cleaved-amplified polymorphic sequences (CAPS) or derived CAPS (dCAPS). These markers were initially tested on pooled L- or S-morph DNA. Out of the 24 markers, 13 allowed for robust amplification and detected the predicted polymorphisms between L- and S-morph pools. These markers were next used to genotype 48 individuals from a natural $P$. veris population in Potsdam, Germany, and based on these data, six markers were found to be linked to the $S$-locus, while the remaining seven showed no clear correlation between marker genotype and $S$-locus phenotype (that is, floral morph; Figure 4). Inspection of the genotypes in Figure 4A indicates that markers 9274, 37812, 41358, 51955, 59102, and 101982 are completely linked to the $S$-locus when considering only the L-morph plants. The genotypes of S-morph plants suggest that in the population there are in fact two common chromosomes harboring the dominant $S$-allele (S-morph). The first is found in phenotypically S-morph plants that are heterozygous for all six markers in question and thus carries S-morph specific alleles at these markers; this chromosome will be termed the 'original S-morph chromosome' below. The other common chromosome is found in phenotypically S-morph plants homozygous for the L-morph allele at markers 9274, 37812, 41358, and 101982. Hence, a recombination event appears to have combined the dominant $S$ allele with the recessive $s$ (L-morph) alleles at these four markers, and the resulting 'recombinant S-morph chromosome' appears to have spread in the local population. No recombination was found among the four markers 9274, 37812, 41358, and 101982. Thus, a tentative, relative marker order deduced from these 48 samples is: (S-locus/51955/59102) - (37812/ $101982 / 9274 / 41358)$, where the markers/loci in brackets cannot be separated from each other. From these six markers we chose four $(51955,59102,37812,101982)$ and genotyped 91 additional individuals (Figure 4B). 


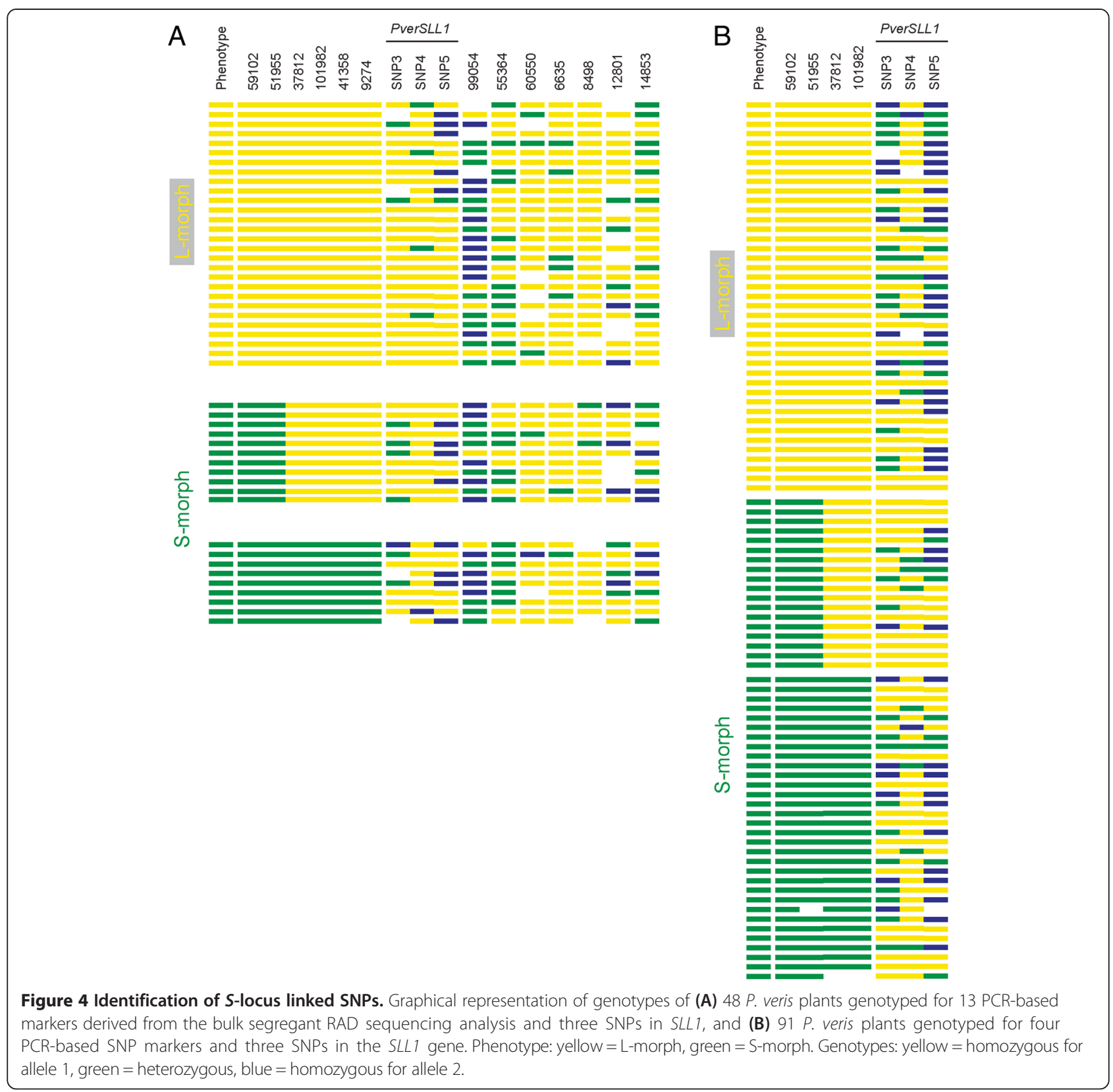

No further recombinant genotypes beyond the ones found in the first 48 plants were detected, thus confirming the deduced order of loci. By blasting the six loci to the $P$. veris genome assembly, we find that markers 37812 and 101982 are both located on Contig437, a result consistent with their complete linkage in the mapping results. Notably, we also find that markers 9274 and 59102 are separated by approximately $70 \mathrm{~Kb}$ on Contig273. Our mapping results suggest that the recombination event that may have given rise to the 'recombinant S-morph chromosome' could have occurred between 9274 and 59102 on Contig273, and this region can thus be considered a functional boundary of the $S$-locus. We also note that the absence of any detectable recombination between four markers (37812, 101982, 9274, and 41358) located on three different scaffolds of considerable size outside of the functional $S$-locus indicates that the suppression of recombination extends over large distances beyond the $S$-locus (see Table 2).

To compare the resolution afforded by our mapping in the natural $P$. veris population to previous reports, we isolated the $P$. veris locus orthologous to the previously described PvSLL1 locus from P. vulgaris [49]. Comparing the sequences of the $P$. veris and the $P$. vulgaris SLL1 locus indicated that one of the internal repeats found in $P$. vulgaris is replaced by an unrelated sequence 
Table 2 Genome scaffolds putatively linked to the $\boldsymbol{P}$. veris $\boldsymbol{S}$-locus

\begin{tabular}{|c|c|c|c|c|c|c|c|c|}
\hline Scaffold ID & Length & Genes & $\mathrm{RE}$ & DE genes & L-morph RNA & S-morph RNA & S-/L-morph SNP ratio & Comments \\
\hline Contig1892 & 36,436 & 1 & 39 & 0 & 5 & 5 & 0 & PVSLL1 (Li et al. [49]) \\
\hline Contig927 & 105,749 & 7 & 104 & $1^{\mathrm{a}}$ & 18 & 20 & 1.1 & PVSLL2 (Li et al. [49]) \\
\hline Contig2830 & 45,782 & 4 & 38 & 0 & 10 & 11 & 1.1 & PveGLO1 (PVGLOP1/P2; Li et al. [60]) \\
\hline Contig1404 & 48,939 & 1 & 31 & 1 & 0 & 0 & 0 & PveGLO2 (PvGLO'; i li et al. [60]) \\
\hline Contig437 & 106,280 & 6 & 52 & 0 & 8 & 40 & 5 & RAD loci 37812 and 101982 \\
\hline Contig478 & 326,606 & 21 & 379 & 2 & 29 & 39 & 1.3 & RAD locus 41358 \\
\hline Contig578 & 132,036 & 14 & 119 & $1^{\mathrm{b}}$ & 16 & 96 & 6 & RAD locus 51955 \\
\hline Contig273 & 185,956 & 11 & 132 & $1^{c}$ & 62 & 98 & 1.5 & RAD loci 9274 and 59102 \\
\hline
\end{tabular}

${ }^{\mathrm{a}}$ Differentially expressed only in $P$. veris floral tissues.

${ }^{b}$ Differentially expressed only in $P$. vulgaris floral tissues.

'Differentially expressed only in $P$. veris leaf tissues.

SNPs identified by mapping RNAseq reads from L- and S-morph flowers to the genome assembly are presented.

$\mathrm{DE}$ Genes = the number of genes on the scaffold that show significant morph-specific differential expression; RE $=$ number of repetitive elements predicted.

in P. veris (Additional file 7: Figure S3). Sequencing this locus from pools of L- and S-morph individuals identified three polymorphic SNPs that were converted to PCR-based genotyping markers. Testing the 139 samples above for these three SNPs indicated no association of any of the SNPs with the $S$-locus genotype, nor an association of any of the resulting seven haplotypes present in the sample with the $S$-locus genotype (Figure 4). Although there was still significant linkage disequilibrium between the three SNPs (Additional file 8: Figure S4; $\mathrm{X}^{2}$-test; $P<0.0001$ ), we identified a substantial proportion of recombinant genotypes, even though the three SNPs are all found within less than $200 \mathrm{bp}$. This suggests that the studied population captures a very large number of historical recombination events resulting in an absence of LD between PvSLL1 and the $S$ locus. Conversely, it indicates that the very tightly linked markers identified above are likely to reside within or immediately next to the $S$-locus.

\section{Genome-wide estimates of heterozygosity and polymorphism}

Heterozygosity and polymorphism were explored in the $P$. veris genome by resequencing a single $P$. veris individual from a Latvian population and mapping these raw sequence reads to our genome assembly. We found a total of $1,184,748$ SNPs $(0.51 \%)$ composed of 982,590 heterozygous sites and 202,158 homozygous sites compared to the reference assembly, and a total of 96,113 indels were identified in the Latvian $P$. veris individual (see Additional file 9).

Theory predicts that the $S$-locus will be largely shielded from recombination [92], and thus $S$-linked genome scaffolds are expected to show elevated rates of heterozygosity in S-morph plants, which are heterozygous at the $S$-locus (Ss), compared to L-morph plants, which are homozygous at the $S$-locus (ss). We evaluated this prediction by mapping RNAseq reads from L- and S-morph plants of $P$. veris to our genome assembly to compare the number of SNPs predicted in coding sequences of genome scaffolds that are putatively linked to the $S$-locus. We found a total of 45,018 SNPs when mapping the L-morph RNA to the genome assembly, and 51,191 SNPs when mapping the $\mathrm{S}$-morph RNA to the genome assembly, and the average $\mathrm{S}$-morph/L-morph SNP ratio for all genome scaffolds is 2.54 (variance $=23.78)$. Table 2 shows the results of this analysis for specific genome scaffolds carrying genes that have been previously identified as linked to the $S$-locus in P. vulgaris: PvSLL1, PvSLL2 [49], PveGLO1, and PveGLO2 [60]. Additionally, we include the genome scaffolds carrying the six loci that are linked to the $S$-locus based on our RAD-seq bulk segregant analysis and fine mapping experiments (see above): RAD loci 41,358, 37,812/101,982, 51,955 , and 9,274/59,102. Our results show that, on average, there are more SNPs mapped from S-morph RNA reads than L-morph RNA reads on putatively $S$-linked scaffolds (Table 2). By utilizing RNAseq reads rather than whole genome sequence data, our analysis is limited to polymorphisms evident in coding regions alone. Additionally, if certain genes experience high degrees of allelespecific expression, we will fail to observe polymorphisms solely due to an absence of mapped reads. It is important to note here that Contig1404, which carries just one gene (PveGLO2), contains no polymorphism when mapping either L- or S-morph RNAseq reads: this is the expected result if PveGLO2 were $S$-linked and only expressed in the $S$-locus of the S-morph. The expectation of increased heterozygosity is fundamentally based on the assumption that individuals with an L-morph phenotype will also be highly homozygous at the $S$-locus. But if recombination is suppressed between L-morph alleles as well, then one might actually expect that linked polymorphisms would accumulate between different L-morph haplotypes, thus leading to elevated heterozygosity at the $S$-locus in L-morph as well as $\mathrm{S}$-morph plants. Addressing this question is beyond the scope of the current study, but future analyses 
aimed at more precisely characterizing genomic patterns of heterozygosity in and around the $S$-locus will benefit greatly from our draft genome assembly of $P$. veris.

\section{Conclusions}

Our $P$. veris genome assembly exemplifies the power of high-throughput DNA sequencing technologies and establishes a benchmark for the rapid de novo assembly of a highly heterozygous, non-model plant with a moderately sized genome (that is, $479.22 \mathrm{Mb}$ ). We believe that the primary strength of our sequencing strategy lies in the diversity of sequence libraries and sequencing platforms we have employed. Our study suggests great promise in the application of PacBio long-read data for the improvement of de novo genome assemblies, and it is possible that, with the direct incorporation of the raw PacBio sequences in the assembly process, even more information could be extracted from long reads. Currently such integration is strongly limited by the a priori correction of raw PacBio reads, which significantly reduces the quantity of usable data resulting from a PacBio run (G. Russo, personal observation). In the case of large eukaryotic genomes, this translates into the need for a largely unfeasible sequencing throughput.

Using our de novo genome assembly coupled with RNAseq data from flower buds, we have identified 113 genes that show significant morph-specific differential expression in both $P$. veris and $P$. vulgaris. Functional analysis of the list of candidate genes has revealed clusters of GO terms related to extracellular processes, cell growth and organization, and development of reproductive structures. Furthermore, our genome assembly shows that the B-function MADS box gene GLOBOSA has been duplicated in Primula, and we find that one of these copies (PveGLO2) is silenced in L-morph flower buds, but we still do not know if PveGLO2 is linked to the $S$-locus, and thus a suitable candidate gene for morph-specific floral development. Future work toward characterizing this candidate gene could involve resequencing both $\mathrm{L}$ - and $\mathrm{S}$-morph plants to evaluate the presence of this gene in both morphs and identify morph-specific SNPs that can be tested for $S$-locus linkage in a mapping population.

Employing a bulk segregant analysis followed by highresolution mapping, we identify six loci on four genome scaffolds that are tightly linked to the $S$-locus in P. veris. When examining these $S$-linked genome scaffolds as well as genome scaffolds carrying genes previously identified as linked to the $S$-locus, we find elevated heterozygosity in S-morph versus L-morph coding sequences, consistent with theoretical predictions. Future work toward defining the recombinational limits and genetic composition of the $S$-locus would benefit greatly from the construction of a linkage map using genetic markers anchored within genome scaffolds. Beyond characterizing the Primula S-locus, our de novo genome sequence will prove to be a valuable resource for marker design and the analysis of population genomic and phylogenomic data. The genomic resources presented here thus represent a significant leap forward in the development of $P$. veris and $P$. vulgaris as models in the study of distyly, climatic adaptation, and speciation genetics.

\section{Materials and methods}

\section{DNA isolation, library preparation, and sequencing}

Genomic DNA was extracted from one L-morph and one $\mathrm{S}$-morph individual of $P$. veris individuals from a cultivated line maintained by the Vogt Stauden nursery [93]. Genomic DNA was extracted from young leaf tissue using two different protocols. The CelLytic PN Isolation/ Extraction Kit (Sigma-Aldrich, Buchs, Switzerland) was used to partially enrich nuclear DNA by following the manufacturer's protocol for 'Crude Preparation of Nuclei', and the resulting product was further purified using a standard CTAB DNA extraction protocol [94]. This genomic DNA is herein referred to as 'partially enriched genomic DNA'. A second sample of 'total genomic DNA' was directly extracted from young leaves following the standard CTAB DNA extraction protocol [94]. For use in estimating the genomic levels of polymorphism (see below), total genomic DNA was extracted from a P. veris individual from a population in the Mazsalaca Municipality in Latvia $\left(57.91494^{\circ} \mathrm{N}, 24.98437^{\circ} \mathrm{E}\right)$. The floral morph of this plant was not noted when the sample was collected, and thus we do not know if this was a L- or S-morph individual. All DNA extractions were quantified using the Broad Range DNA Kit on a Qubit v.2.0 spectrophotometer (Life Technologies, Zug, Switzerland), and the presence of high molecular weight DNA was confirmed by $1 \%$ agarose-gel electrophoresis stained with $1 \%$ ethidium bromide.

Genomic DNA was prepared for sequencing by generating three different types of libraries. An overview of the library types employed for the assembly and their summary statistics are shown in Table 1. The small fragment library was prepared using the Illumina Paired-End DNA protocol. The average fragment size was 180 nucleotides and the fragments were sequenced on an Illumina HiSeq 2000 in paired-end mode. The length of 100 bases for both the forward and reverse reads ensured a small overlap across the read pairs, a feature recommended for de novo assembly. Mate-pair libraries were produced by circularizing DNA fragments of different lengths using a biotinylated internal adapter. The circular fragments were then sheared and the biotinylated segments were detected and amplified for sequencing. Illumina Nextera long mate-pair protocol and Life Technologies mate-pair protocol, which are based on the above-mentioned approach, were both applied and the resulting libraries were sequenced on Illumina HiSeq2000 and MiSeq instruments 
and on Life Technologies Ion Proton System, respectively. Libraries prepared from fragments of three different sizes ( $3 \mathrm{~Kb}, 6 \mathrm{~Kb}$, and $9 \mathrm{~Kb}$ ) were selected for sequencing on the Illumina technologies, whereas only libraries generated from $3 \mathrm{~Kb}$ fragments were sequenced on the Ion Proton. Finally, long fragment DNA templates were produced following the Pacific Biosciences (PacBio) $10 \mathrm{~kb}$ library protocol and sequenced on 25 SMRT cells of the PacBio RS II.

\section{Genome assembly}

Fragments sequenced in paired-end mode on the Illumina HiSeq were stripped of the sequencing adapters without further preprocessing, due to the high quality of the sequencing run. Sequences produced from the mate-pair libraries had both external and internal adapters removed. Mate-pairs resulting from templates sequenced on platforms generating reads of variable length (that is, MiSeq and IonProton) were retained only if both the forward and the reverse reads contained at least 30 nucleotides after adapter removal. Long fragments sequenced on the Pacific Bioscience RSII had the SMRTbell adapters removed and filtered according to a minimum read length of 50 nucleotides and a minimum read quality of $75 \%$.

The final draft of the P.veris genome was obtained using a two-step procedure.

De novo assembly was performed using ALLPATHS-LG v48579 [95], with specific settings for a diploid organism (that is, by setting PLOIDY = 2) and provided with a genome size estimate of $445 \mathrm{Mb}$ [65]. Data from the genomic templates sequenced on the Pacific Biosciences (PacBio) RS II were not used at this stage, as ALLPATHS-LG relies on paired reads information (either paired-end or mate pairs) and discourages the use of long fragment reads when assembling large eukaryotic organisms. Long fragment reads were only successively incorporated to perform gap-closing and further scaffolding of the first assembly draft using PBJelly v14.1.15 [67]. The PacBio readalignment software 'blasr' was provided with the following settings: minMatch $=8$, sdpTupleSize $=8$, minPctIdentity $=$ 75, best $=1, n$ Candidates $=10, \operatorname{maxScore}=500$, and noSplitSubreads was activated.

\section{RNA isolation, library preparation, and sequencing}

With the aim of sequencing a diverse transcript pool, total RNA was isolated separately from floral and leaf tissues for each plant sampled in our study. Entire, mature floral buds, 3 to 5 days prior to anthesis were used for RNA extraction from floral tissues. Leaf tissues were sampled approximately 4 to 6 days prior to complete leaf blade expansion. RNA was isolated from a $P$. veris $\mathrm{L}$-morph plant (Vogt 026-P) and from a $P$. veris S-morph plant (VE8-T). For comparative analyses, we also extracted floral bud RNA from $P$. vulgaris L-morph (VU2-P) and S-morph
(VU-T37) plants 3 to 5 days prior to anthesis. Total RNA was extracted using the RNAqueous Kit (Life Technologies, Zug, Switzerland) following the manufacturer's standard protocol. Extracted RNA was quantified using a Qubit v2 fluorometer RNA assay kit (Life Technologies) and diluted to $40 \mathrm{ng} / \mu \mathrm{L}$ for subsequent library construction. For all six samples, the standard unstranded Illumina TruSeq protocol was used, which includes a step to pull down polyadenylated transcripts from the cDNA pool. Libraries were then multiplexed using a set of six Illumina barcodes and sequenced on one lane of an Illumina HiSeq 2000 instrument in paired-end mode.

\section{Transcriptome assembly and comparative analysis}

Transcriptome assemblies were generated for each species using either the raw Illumina sequence data from $P$. veris and $P$. vulgaris RNAseq runs or data downloaded from Genbank for P. obconica, P. wilsonii, and P. poissonii [66]. Adaptor sequences were removed from the raw sequencing reads, and reads with a quality score below 15 were removed. De novo transcriptome assembly was performed using the Trinity software suite v.2013-8-14 [96,97] using default parameters. The likely coding DNA sequences (CDS) and corresponding proteins within the de novo transcriptome assembly were estimated with Transdecoder [98]. Redundant transcripts potentially representing sequencing errors or genetic polymorphisms were clustered with the cd-hit software [99].

Protein sequences from the cd-hit results of the $P$. veris, $P$. vulgaris, $P$. obconica, $P$. wilsonii, and $P$. poissonii transcriptomes were used to identify clusters of putatively orthologous genes using OrthoMCL v.2.0.9 [79,80]. Pairwise sequence similarities between all protein sequences were calculated with blastp using an e-value cutoff of 1e05 . Using these results, protein clusters that are roughly equivalent to orthologous groups were estimated using the Markov clustering algorithm employed in OrthoMCL with the default inflation value $(-\mathrm{I})$ of 1.5. A second OrthoMCL analysis was performed using identical parameters in order to identify putative orthologs with $P$. veris among a broader sample of sequenced and annotated Euasteridae genomes, including tomato (Solanum lycopersicum; [68]), grape (Vitis vinifera; [70]), kiwifruit (Actinidia chinensis; [69]), and monkeyflower (Mimulus guttatus; Mimulus Genome Project, DoE Joint Genome Institute).

\section{Gene prediction and annotation}

Genome annotation was performed using the Maker2 pipeline [78]. Augustus v2.7 [100] and SNAP (Release 201311-29; [101]) were used as $a b$ initio gene predictors. The Trinity-assembled $P$. veris transcripts (see above) were used as transcript evidence. Protein sequences from the Arabidopsis thaliana genome (version TAIR10) were used as homology-based evidence. Repetitive genomic 
elements were identified and masked from annotation with RepeatMasker [102] using the Repbase database [103]. The Maker2 annotation was first run using the de novo transcriptome directly to infer gene predictions (that is, est2genome $=1$ ), and training files for the ab initio gene predictors Augustus and SNAP were generated based on these results. The annotation pipeline was then run iteratively two additional times using the assembled $P$. veris transcriptome as evidence (that is, est2genome $=0$ ) and providing new training files with each run. At this point, the protein-homology set was broadened to include all Uniprot proteins in the Embryophyta and a final annotation was performed by also providing Maker2 with the transcript-annotation file (in .gff format) obtained from the previous runs (that is, 'pass-through' aided annotation). InterProScan v.5 was used to identify PFAM domains [104] in the predicted $P$. veris protein sequences using default parameters [105]. The predicted $P$. veris protein sequences were searched against a set of 248 highly conserved core eukaryotic genes using the CEGMA pipeline [77].

\section{Estimating heterozygosity and polymorphism}

To estimate genome-wide patterns of heterozygosity and polymorphism, a single $P$. veris individual from near the northern range limit of the species in Latvia (see above) was resequenced. A total of 158.8 million paired-end reads were generated on one-third of a single lane of an Illumina HiSeq instrument, yielding about $16 \mathrm{~Gb}$ of data. The resulting reads were mapped to the newly constructed $P$. veris reference assembly using Bowtie2 [106] with paired-end settings and -local-sensitive parameters. Insertion/deletions and SNPs were called using a combination of SAMtools v0.1.19 and Bcftools v0.1.19 [107] with default settings. Polymorphisms reported as purely diploid with a minimum coverage of $30 \times$, a maximum coverage of $300 \times$, and a minimum quality score of 50 were retained.

Genomic regions within and tightly linked to the S-locus are expected to be more heterozygous in S-morph than in L-morph plants [92]. To identify genome scaffolds with elevated heterozygosity in coding regions of S-morph versus L-morph plants, we mapped the raw RNAseq reads from L-morph and S-morph individuals back to the P. veris genome assembly. The positions of SNPs and indels in the $P$. veris draft genome assembly are provided in Additional files 9 and 10.

\section{Gene expression differences between floral morphs}

In order to perform differential expression analysis, the final assembly was used as reference genome and the genomic features annotated by Maker2 acted as gtf annotation file.

The reads produced by sequencing the six RNA samples were mapped using STAR aligner [108] with default parameter settings. CountOverlap from the Bioconductor package GenomicRanges [109] was used to summarize the overlaps between the reads and the annotated features, and based on this information the Bioconductor tool edgeR [110] was employed to test for differentially expressed genes. Three pairwise comparisons were performed: (1) L- and S-morph floral RNA from P. veris; (2) L- and S-morph floral RNA from P. vulgaris; and (3) L- and S-morph leaf RNA from $P$. veris. Genes were determined to exhibit significant differential expression between samples if the $P$ value (corrected for FDR) was below 0.05 . Further validation of differential expression was accomplished by cross-referencing the $P$. veris L-morph versus $\mathrm{S}$-morph floral genes with $P$. vulgaris $\mathrm{L}$-morph versus $\mathrm{S}$-morph floral genes. The set of cross-referenced genes showing significant morph-specific differential expression was examined for enrichment of gene ontology (GO) terms using the DAVID Bioinformatics Resources v6.7 [81]. The set of $113 P$. veris genes showing morph-specific differential expression was searched against $A$. thaliana proteins (TAIR10) to identify homologous genes using blastp with an e-value cutoff of 10e-3. A total of 92 A. thaliana homologues were confidently identified, and the remaining 21 genes were not included in the GO terms analysis. Functional annotation clustering and enrichment analyses were performed with DAVID using default settings and the default $A$. thaliana background.

\section{Bulk segregant analysis to identify loci linked to the $P$. veris $S$-locus and $\mathrm{PCR}$-based genotyping}

Genomic DNA was extracted from two pools of over $100 \mathrm{~L}$-morph or over $100 \mathrm{~S}$-morph individuals collected from a large population of $P$. veris plants in Park Sanssouci in Potsdam, Germany, following the protocol above (see DNA Isolation, Library Preparation, and Sequencing). Restriction-associated DNA sequencing (RAD-seq; [111]) using Pst $\mathrm{I}$ was performed on these pooled genomic DNAs by Floragenex (Oregon, USA). A total of 43 and 52 million Illumina paired-end sequence reads were obtained for the L- and S-morph pools, respectively. From these pairedend sequences, contigs flanking the PstI-sites were assembled, and reads from the pooled L- and S-morph samples were aligned to these contigs to detect and catalogue polymorphisms. Polymorphisms putatively linked to the $S$-locus were identified using custom perl scripts that parsed a variant call format (VCF) file cataloging the SNPs observed in the sequenced $P$. veris pools. Briefly, in order to consider a variant as linked, several criteria needed to be met. First, the sequencing coverage for any candidate allele in both pools needed to exceed $60 \times$. The allele frequency for each variant in both the L-morph and S-morph pools was then estimated by counting the number of sequence reads in each pool harboring either the reference or alternate allele, divided by the total number 
of reads covering the specific variant in that pool. Note the sequencing coverage and allele counts for all loci are documented in the VCF file. Finally, in order to identify variants strongly linked to the $S$-locus we screened for variants that had an allele frequency in the L-morph pool of 1.0, while the allele frequency in S-morph pool could range between 0.3 and 0.7 .

To test linkage of candidate polymorphisms to the $S$-locus, polymorphisms identified from the bulk segregant RAD-seq analysis were converted to CAPS and dCAPS markers using dCAPS Finder 2.0 [112]. Genomic DNA from individual L- and S-morph plants from the Sanssouci population was isolated using the CTAB method [94]. PCR products were digested with the appropriate restriction enzymes overnight, before resolving on 3\% agarose gels. Details of the primers and corresponding restriction enzymes used are given in Additional file 1: Table S6.

\section{Data availability}

The genome assembly and raw sequence data generated in this study are available at NCBI under the BioProject ID PRJNA238546. The data from the bulk segregant RADseq analysis are available under NCBI BioProject ID PRJNA268094. The Maker2 annotation files are available for download at Dryad (http://www.datadryad.org/) under doi:10.5061/dryad.2s200.

\section{Additional files}

Additional file 1: Table S1. Summary of de novo genome assemblies, Table S2. RNAseq sequencing results for $P$. veris and $P$. vulgaris. Table S3. Repeat content of the $P$. veris genome assembly predicted by RepeatMasker. Table S4. List of genes with floral morph-specific differential expression in $P$. veris and $P$. vulgaris. Table S5. Functional Annotation Cluster Analysis of genes showing morph-specific differential expression. Table S6. Primer sequences for CAPS and dCAPS genotyping of RAD markers.

Additional file 2: Figure S1. PacBio RS data. Histogram showing the distribution of $(\mathbf{A})$ read length and $(\mathbf{B})$ read quality from the PacBio RS data. obconica, P. wilsonii, and P. poissonii.

Additional file 3: Figure S2. Cumulative annotation edit distance (AED). AED plotted for 5 iterative Maker2 annotations runs. Run $1=$ black, run $2=$ blue, run 3 =yellow, run $4=$ orange, final run $5=$ red.

Additional file 4: All putatively single copy orthologous genes identified between $P$. veris, $P$. vulgaris, $P$.

Additional file 5: All putatively single copy orthologous genes identified between $P$. veris, S. lycopersicum (tomato), M. guttatus (monkeyflower), V. vinifera (grape), and A. chinensis (kiwifruit).

Additional file 6: List of 24 RAD loci carrying SNPs identified as linked to the $P$. veris $S$-locus.

Additional file 7: Figure S3. Comparison of SLL1 gene between P. vulgaris and $P$. veris. Schematic representation of the indicated SLL1 alleles from $P$. vulgaris and $P$. veris. Data for $P$. vulgaris are from Li et al. [49]. Replacement of the internal repeat by the unrelated sequence in $P$. veris was confirmed by PCR.

Additional file 8: Figure S4. Test of linkage between SLL1 haplotypes and the $S$ locus in P. veris. (A) Frequency of diploid genotypes observed in L- and S-morph plants and component haplotypes. (B) Frequency of SLL1 haplotypes in L- and S-morph plants, and expected frequency per haplotype under the assumption of no LD between the three component SNPs. Yellow: homozygous for allele 1; blue: homozygous for allele 2; green: heterozygous.

Additional file 9: A tab-delimited file showing the position of all SNPs based on the resequencing of a $P$. veris plant from Latvia.

Additional file 10: Tab-delimited files showing the position of all SNPs identified by mapping RNAseq reads from $P$. veris $L$-morph flower buds, L-morph leaves, S-morph flower buds, and S-morph leaves, respectively, to the $P$. veris genome assembly.

\section{Abbreviations}

AED: annotation edit distance; bp: base pairs; CAPS: cleaved amplified polymorphic sequences; CDS: coding DNA sequences; CEGs: conserved eukaryotic genes; CTAB: cetrimonium bromide; dCAPS: derived cleaved amplified polymorphic sequences; FDR: false discovery rate; GO: gene ontology; indel: insertion/deletion polymorphism; LD: linkage disequilibrium; PCR: polymerase chain reaction; RAD: restriction-associated DNA; S-locus: self-incompatibility locus; SNP: single nucleotide polymorphism; SRA: Sequence Read Archive; UTR: untranslated region.

\section{Competing interests}

The authors declare that they have no competing interests.

\section{Authors' contributions}

MN conceived of the study, participated in its design and coordination, performed analyses, and wrote the manuscript. GR participated in study design and coordination, performed analyses, and helped draft the manuscript. RS participated in study design and coordination. ML and $\mathrm{CH}$ participated in study design and coordination, performed analyses, and helped draft the manuscript. EC conceived of the study, participated in its design and coordination, and helped draft the manuscript. All authors read and approved the final manuscript.

\section{Acknowledgements}

This study was supported by funding from the University of Zurich and the G. \& A. Claraz-Schenkung Foundation. The authors would like to thank Catherine Aquino, Andrea Patrignani, and Lucy Poveda for their invaluable work at the FGCZ labs, Friederike Jantzen for help with P. veris genotyping, and Jörg Wacker (Stiftung Preussische Schlösser und Gärten) for permission to sample the $P$. veris population in Park Sanssouci.

\section{Author details}

'Institute of Systematic Botany, University of Zürich, Zollikerstrasse 107, 8008 Zürich, Switzerland. ${ }^{2}$ Natural History Museum, University of Oslo, P.O. Box 1172, Blindern NO-0318, Oslo, Norway. ${ }^{3}$ Functional Genomics Center Zürich, University of Zürich and ETH Zürich, Winterthurerstrasse 190, 8057 Zürich, Switzerland. ${ }^{4}$ Institut für Biochemie und Biologie, Universität Potsdam, Karl-Liebknecht-Strasse 24-25, Haus 26, 14476 Potsdam, Germany.

Received: 21 May 2014 Accepted: 11 December 2014 Published online: 24 January 2015

\section{References}

1. Scheffers BR, Joppa LN, Pimm SL, Laurance WF (2012) What we know and don't know about Earth's missing biodiversity. Trends Ecol Evol 27:501-10

2. Grant V (1949) Pollination systems as isolating mechanisms in angiosperms. Evolution 3:82-97

3. Crane PR, Friis EM, Pedersen KR (1995) The origin and early diversification of angiosperms. Nature 374:27-33

4. Charlesworth D, Charlesworth B (1987) Inbreeding depression and its evolutionary consequences. Annu Rev Ecol Syst 18:237-68

5. Wright SI, Ness RW, Foxe JP, Barrett SCH (2008) Genomic consequences of outcrossing and selfing in plants. Int J Plant Sci 169:105-18

6. Darwin C (1877) The Different Forms of Flowers on Plants of the Same Species. John Murray, London

7. Barrett S (2002) The evolution of plant sexual diversity. Nat Rev Genet 3:274-84

8. McCubbin A. Heteromorphic self-incompatibility in Primula: twenty-first century tools promise to unravel a classic nineteenth century model system. 2008. p. 289-308. 
9. Keller B, de Vos JM, Conti E (2012) Decrease of sexual organ reciprocity between heterostylous primrose species, with possible functional and evolutionary implications. Ann Bot 110:1233-44

10. Keller B, Thomson JD, Conti E (2014) Heterostyly promotes disassortative pollination and reduces sexual interference in Darwin's primroses: evidence from experimental studies. Funct Ecol 28:1413-25

11. Barrett SCH (1992) Heterostylous genetic polymorphisms: model systems for evolutionary analysis. Monographs on Theoretical and Applied Genetics 15:1-29

12. Richards A (2003) Primula. Timber Press, Portland, OR

13. Mast A, Kelso S, Conti E (2006) Are any primroses (Primula) primitively monomorphic? New Phytol 171:605-16

14. de Vos JM, Hughes CE, Schneeweiss GM, Moore BR, Conti E (2014) Heterostyly accelerates diversification via reduced extinction in primroses. P R Soc B 281:20140075-5

15. Guggisberg A, Mansion G, Kelso S, Conti E (2006) Evolution of biogeographic patterns, ploidy levels, and breeding systems in a diploid-polyploid species complex of Primula. New Phytol 171:617-32

16. Guggisberg A, Mansion G, Conti E (2009) Disentangling reticulate evolution in an arctic-alpine polyploid complex. Systematic Biol 58:55-73

17. Theodoridis S, Randin C, Broennimann O, Patsiou T, Conti E (2013) Divergent and narrower climatic niches characterize polyploid species of European primroses in Primula sect. Aleuritia J Biogeogr 40:1278-89

18. Casazza G, Granato L, Minuto L, Conti E (2012) Polyploid evolution and Pleistocene glacial cycles: A case study from the alpine primrose primula marginata (primulaceae). BMC Evol Biol 12:56

19. Schorr G, Pearman PB, Guisan A, Kadereit JW (2013) Combining palaeodistribution modelling and phylogeographical approaches for identifying glacial refugia in Alpine Primula. J Biogeogr 40:1947-60

20. de Vos JM, Keller B, Isham ST, Kelso S, Conti E (2012) Reproductive implications of herkogamy in homostylous primroses: variation during anthesis and reproductive assurance in alpine environments. Funct Ecol 26:854-65

21. Nishihiro J, Washitani I, Thomson J, Thomson B (2000) Patterns and consequences of stigma height variation in a natural population of a distylous plant. Primula sieboldii. Funct Ecol 14:502-12

22. Dowrick VPJ (1956) Heterostyly and homostyly in Primula obconica. Heredity 10:219-36

23. Lewis D, Jones DA (1992) The genetics of heterostyly. In: Barrett SCH (ed) Evolution and function of heterostyly. Springer-Verlag, New York, pp 129-50

24. Kurian V, Richards A (1997) A new recombinant in the heteromorphy " $\mathrm{S}$ " supergene in Primula. Heredity 78:383-90

25. Wedderburn F, Richards A (1992) Secondary homostyly in Primula L - evidence for the model of the S-supergene. New Phytol 121:649-55

26. Ernst A. Stammesgeschicktliche Untersuchungen zum Heterostylie-Problem - 7 Stand des Nachweises monomorpher Arten, homostyler Sippen und anderer genetisch bedingter Abweichungen vom "klassischen" Blütendimorphismus in den Sektionen der Gattung Primula. Archiv der Julius Klaus-Stiftung. 1962; XXXVII:1-127.

27. Mast A, Conti E (2006) The primrose path to heterostyly. New Phytol 171:439-42

28. de Vos JM, Wüest RO, Conti E (2014) Small and ugly? Phylogenetic analyses of the "selfing syndrome" reveal complex evolutionary fates of monomorphic primrose flowers. Evolution 68:1042-57

29. Jiménez A, Mansour H, Keller B, Conti E (2013) Low genetic diversity and high levels of inbreeding in the Sinai primrose (Primula boveana), a species on the brink of extinction. Plant Syst Evol 300:1199-208

30. Ishihama F, Ueno S, Tsumura Y, Washitani I (2006) Effects of density and floral morph on pollen flow and seed reproduction of an endangered heterostylous herb. Primula sieboldii. J Ecol 94:846-55

31. Schmidt-Lebuhn AN, de Vos JM, Keller B, Conti E (2012) Phylogenetic analysis of Primula section Primula reveals rampant non-monophyly among morphologically distinct species. Mol Phylogenet Evol 65:23-34

32. Valentine D (1947) Studies in British Primulas. I. Hybridization between primrose and oxlip (Primula vulgaris Huds. and P. elatior Schreb.). New Phytol 46:229-53

33. Valentine D (1952) Studies in British Primulas. III. Hybridization between Primula elatior (L.) Hill and P. veris L. New Phytol 50:383-99

34. Valentine D (1955) Studies in British Primulas. IV. Hybridization between Primula vulgaris Huds. and P. veris L. New Phytol 54:70-80

35. Clifford H (1958) Studies in British Primulas. VI. On introgression between primrose (Primula vulgaris Huds.) and cowslip (P. veris L.). New Phytol 57:1-10
36. Woodell S (1960) Studies in British Primulas. VII. Development of normal seed and of hybrid seed from reciprocal crosses between P. vulgaris Huds. and P. veris L. New Phytol 59:302-13

37. Woodell S (1965) Natural hybridizationbetween the cowsip (Primula veris L.) and the primrose (P. vulgaris Huds.) in Britain. Watsonia 6:190-202

38. Kálmán K, Medvegy A, Penzes Z, Mihalik E (2007) Morph-specific variation of floral traits associated with reciprocal herkogamy in natural populations of Primula vulgaris and Primula veris. Plant Syst Evol 268:15-27

39. Pugsley H (1927) Primula hybrids. Journal of Botany 65:351

40. Brys R, Jacquemyn H (2009) Biological Flora of the British Isles: Primula veris L. J Ecol 97:581-600

41. Jacquemyn H, Vandepitte K, Roldan-Ruiz I, Honnay O (2009) Rapid loss of genetic variation in a founding population of Primula elatior (Primulaceae) after colonization. Ann Bot 103:777-83

42. Brys $R$, Jacquemyn $H$, Endels $P$, Van Rossum F, Hermy M, Triest $L$ et al (2004) Reduced reproductive success in small populations of the self-incompatible Primula vulgaris. J Ecol 92:5-14

43. Jacquemyn H, Brys R, Hermy M (2002) Patch occupancy, population size and reproductive success of a forest herb (Primula elatior) in a fragmented landscape. Oecologia 130:617-25

44. Ornduff R (1979) Pollen flow in a population of Primula vulgaris Huds. Bot J Linn Soc 78:1-10

45. Ornduff R (1980) Heterostyly, population composition, and pollen flow in Hedyotis caerulea. Am J Bot 67:95-103

46. Van Rossum F, Triest $L$ (2006) Within-population genetic variation in the distylous Primula veris: Does floral morph anisoplethy matter in fragmented habitats? Perspectives in Plant Ecology. Evolution and Systematics 7:263-73

47. Webster M, Gilmartin P (2003) A comparison of early floral ontogeny in wild-type and floral homeotic mutant phenotypes of Primula. Planta 216:903-17

48. Webster M, Gilmartin P (2006) Analysis of late stage flower development in Primula vulgaris reveals novel differences in cell morphology and temporal aspects of floral heteromorphy. New Phytol 171:591-603

49. Li J, Webster M, Furuya M, Gilmartin P (2007) Identification and characterization of pin and thrum alleles of two genes that co-segregate with the Primula S locus. Plant J 51:18-31

50. Li J, Webster M, Smith M, Gilmartin P (2011) Floral heteromorphy in Primula vulgaris: progress towards isolation and characterization of the $\mathrm{S}$ locus. Ann Bot 108:715-26

51. McCubbin A, Lee C, Hetrick A (2006) Identification of genes showing differential expression between morphs in developing flowers of Primula vulgaris. Sex Plant Reprod 19:63-72

52. Heslop-Harrison Y, Heslop-Harrison J, Shivanna K (1981) Heterostyly in Primula. 1. Fine-structural and cytochemical features of the stigma and style in Primula vulgaris Huds. Protoplasma 107:171-87

53. Cohen J (2010) "A case to which no parallel exists": The influence of Darwin's different forms of flowers. Am J Bot 97:701-16

54. Bateson W, Gregory R (1905) On the inheritance of heterostylism in Primula. Proceedings of the Royal Society of London Series B, Containing Papers of a Biological Character 76:581-6

55. Haldane J (1938) Heterostylism in natural populations of the primrose, Primula acaulis. Biometrika 30:196-8

56. Ernst A (1957) Austausch und Mutation im Komplex-Gen für Blütenplastik und Inkompatibilität bei Primula. Mol Gen Genet MGG 88:517-99

57. Mather K (1950) The genetical architecture of heterostyly in Primula sinensis. Evolution 4:340-52

58. Barrett S, Shore J (2008) New insights on heterostyly: comparative biology, ecology and genetics. In: Franklin-Tong VE (ed) Self-incompatibility in flowering plants. Springer, New York, pp 3-32

59. Schwander T, Libbrecht R, Keller $L$ (2014) Supergenes and complex phenotypes. Curr Biol 24:R288-94

60. Li J, Webster M, Dudas B, Cook H, Manfield I, Davies B et al (2008) The S locus-linked Primula homeotic mutant sepaloid shows characteristics of a B-function mutant but does not result from mutation in a B2 function gene. Plant J 56:1-12

61. Muller $\mathrm{H}$ (1964) The relation of recombination to mutational advance. Mutat Res 1:2-9

62. Lloyd DG (1992) The evolution of heterostyly. In: Barrett SCH (ed) Evolution and function of heterostyly. Springer, Berlin, pp 151-78

63. Charlesworth D, Charlesworth B (1979) A model for the evolution of distyly. Am Nat 114:467-98 
64. Shore J, Arbo M, Fernandez A (2006) Breeding system variation, genetics and evolution in the Turneraceae. New Phytol 171:539-51

65. Siljak-Yakovlev S, Pustahija F, Bogunić F, Šolić EM, Muratović E, Bašić N et al (2010) Towards a genome size and chromosome number database of Balkan flora: C-values in 343 taxa with novel values for 242. Adv Sci Lett 3:190-213

66. Zhang L, Yan H-F, Wu W, Yu H, Ge X-J (2013) Comparative transcriptome analysis and marker development of two closely related Primrose species (Primula poissonii and Primula wilsonii). BMC Genomics 14:329

67. English AC, Richards S, Han Y, Wang M, Vee V, Qu J et al (2012) Mind the gap: upgrading genomes with Pacific biosciences RS long-read sequencing technology. PLoS One 7:e47768

68. Tomato Genome Consortium (2012) The tomato genome sequence provides insights into fleshy fruit evolution. Nature 485:635-41

69. Huang S, Ding J, Deng D, Tang W, Sun H, Liu D et al (2013) Draft genome of the kiwifruit Actinidia chinensis. Nat Commun 4:1-9

70. Jaillon O, Aury J-M, Noel B, Policriti A, Clepet C, Casagrande A et al (2007) The grapevine genome sequence suggests ancestral hexaploidization in major angiosperm phyla. Nature 449:463-7

71. Velasco R, Zharkikh A, Affourtit J, Dhingra A, Cestaro A, Kalyanaraman A et al (2010) The genome of the domesticated apple (Malus $\times$ domestica Borkh.). Nat Genet 42:833-9

72. He N, Zhang C, Qi X, Zhao S, Tao Y, Yang G et al (2013) Draft genome sequence of the mulberry tree Morus notabilis. Nat Commun 4:1-9

73. van Bakel H, Stout JM, Cote AG, Tallon CM, Sharpe AG, Hughes TR et al (2011) The draft genome and transcriptome of Cannabis sativa. Genome Biol 12:R102

74. Chagné D, Crowhurst RN, Pindo M, Thrimawithana A, Deng C, Ireland H et al (2014) The draft genome sequence of European pear (Pyrus communis L. "Bartlett"). PLoS One 9:e92644

75. Swarbreck D, Wilks C, Lamesch P, Berardini TZ, Garcia-Hernandez M, Foerster H et al (2007) The Arabidopsis Information Resource (TAIR): gene structure and function annotation. Nucleic Acids Res 36:D1009-14

76. Ming R, VanBuren R, Liu Y, Yang M, Han Y, Li L-T et al (2013) Genome of the long-living sacred lotus (Nelumbo nucifera Gaertn.). Genome Biol 14:R41

77. Parra G, Bradnam K, Korf I (2007) CEGMA: a pipeline to accurately annotate core genes in eukaryotic genomes. Bioinformatics 23:1061-7

78. Holt C, Yandell M (2011) MAKER2: an annotation pipeline and genome-database management tool for second-generation genome projects. BMC Bioinformatics 12:491

79. Li L (2003) OrthoMCL: Identification of ortholog groups for eukaryotic genomes. Genome Res 13:2178-89

80. Fischer S, Brunk BP, Chen F, Gao X, Harb OS, lodice JB et al (2011) Using OrthoMCL to assign proteins to OrthoMCL-DB groups or to cluster proteomes into new ortholog groups. John Wiley \& Sons, Inc., Hoboken, NJ

81. Huang DW, Sherman BT, Lempicki RA (2008) Systematic and integrative analysis of large gene lists using DAVID bioinformatics resources. Nat Protoc 4:44-57

82. Richards A, Ibrahim H (1982) The breeding system in Primula veris L. II Pollen tube growth and seed-set. New Phytol 90:305-14

83. Wedderburn F, Richards A (1990) Variation in within-morph incompatibility inhibition sites in heteromorphic Primula L. New Phytol 116:149-62

84. Shivanna K, Heslop-Harrison J, Heslop-Harrison Y (1981) Heterostyly in Primula. 2. Sites of pollen inhibition, and effects of pistil constituents on compatible and incompatible pollen-tube growth. Protoplasma 107:319-37

85. Gibbs P (1986) Do homomorphic and heteromorphic self-incompatibility systems have the same sporophytic mechanism? Plant Syst Evol 154:285-323

86. Barrett SCH, Cruzan M (1994) Incompatibility in heterostylous plants. In: Williams EG, Clarke AE, Knox RB (eds) Genetic control of self-incompatibility and reproductive development in flowering plants. Springer, Netherlands, pp 189-219

87. Carraro L, Lombardo G, Gerola P (1996) Stylar peroxidases and heteromorphic incompatibility reactions in Primula acaulisHill («thrum» morph). Caryologia 49:101-12

88. Richards JH, Barrett S (1992) The development of heterostyly. In: Barrett SCH (ed) Evolution and function of heterostyly. Springer, New York, pp 85-127

89. Krizek BA, Meyerowitz EM (1996) The Arabidopsis homeotic genes APETALA3 and PISTILLATA are sufficient to provide the B class organ identity function. Development 122:11-22

90. Tröbner W, Ramirez L, Motte P, Hue I, Huijser P, Lönnig WE et al (1992) GLOBOSA: a homeotic gene which interacts with DEFICIENS in the control of Antirrhinum floral organogenesis. EMBO J 11:4693-704
91. Viaene T, Vekemans D, Irish VF, Geeraerts A, Huysmans S, Janssens $S$ et al (2009) Pistillata-duplications as a mode for floral diversification in (Basal) asterids. Mol Biol Evol 26:2627-45

92. Uyenoyama M (2005) Evolution under tight linkage to mating type. New Phytol 165:63-70

93. Vogt Stauden. http://www.vogtstauden.ch/. Accessed 21 Dec 2014.

94. Murray MG, Thompson WF (1980) Rapid isolation of high molecular weight plant DNA. Nucleic Acids Res 8:4321-5

95. Gnerre S, MacCallum I, Przybylski D, Ribeiro FJ, Burton JN, Walker BJ et al (2011) High-quality draft assemblies of mammalian genomes from massively parallel sequence data. Proc Natl Acad Sci 108:1513-8

96. Grabherr MG, Haas BJ, Yassour M, Levin JZ, Thompson DA, Amit I et al (2011) Full-length transcriptome assembly from RNA-Seq data without a reference genome. Nat Biotechnol 29:644-52

97. Haas BJ, Papanicolaou A, Yassour M, Grabherr M, Blood PD, Bowden J et al (2013) De novo transcript sequence reconstruction from RNA-seq using the Trinity platform for reference generation and analysis. Nat Protoc 8:1494-512

98. TransDecoder. http://transdecoder.sourceforge.net/. Accessed 21 Dec 2014

99. Fu L, Niu B, Zhu Z, Wu S, Li W (2012) CD-HIT: accelerated for clustering the next-generation sequencing data. Bioinformatics 28:3150-2

100. Stanke M, Diekhans M, Baertsch R, Haussler D (2008) Using native and syntenically mapped cDNA alignments to improve de novo gene finding. Bioinformatics 24:637-44

101. Korf I (2004) Gene finding in novel genomes. BMC Bioinformatics 5:59 102. RepeatMasker. http://www.repeatmasker.org. Accessed 21 Dec 2014.

103. Jurka J, Kapitonov W, Pavlicek A, Klonowski P, Kohany O, Walichiewicz J (2005) Repbase Update, a database of eukaryotic repetitive elements. Cytogenet Genome Res 110:462-7

104. Punta M, Coggill PC, Eberhardt RY, Mistry J, Tate J, Boursnell C et al (2011) The Pfam protein families database. Nucleic Acids Res 40:D290-301

105. Quevillon E, Silventoinen V, Pillai S, Harte N, Mulder N, Apweiler R et al (2005) InterProScan: protein domains identifier. Nucleic Acids Res 33:W116-20

106. Langmead B, Salzberg SL (2012) Fast gapped-read alignment with Bowtie 2. Nat Meth 9:357-9

107. Li H, Handsaker B, Wysoker A, Fennell T, Ruan J, Homer N et al (2009) The Sequence Alignment/Map format and SAMtools. Bioinformatics 25:2078-9

108. Dobin A, Davis CA, Schlesinger F, Drenkow J, Zaleski C, Jha S et al (2012) STAR: ultrafast universal RNA-seq aligner. Bioinformatics 29:15-21

109. Lawrence M, Huber W, Pagès $H$, Aboyoun P, Carlson M, Gentleman R et al (2013) Software for computing and annotating genomic ranges. PLoS Comput Biol 9:e1003118

110. Robinson MD, Smyth GK. edgeR: a Bioconductor package for differential expression analysis of digital gene expression data. Bioinformatics. 2009;26:139-40.

111. Baird N, Etter P, Atwood T, Currey M, Shiver A, Lewis Z et al (2008) Rapid SNP discovery and genetic mapping using sequenced RAD markers. PLoS One 3:e3376

112. Neff MM, Turk E, Kalishman M (2002) Web-based primer design for single nucleotide polymorphism analysis. Trends Genet 18:613-5

\section{Submit your next manuscript to BioMed Central and take full advantage of:}

- Convenient online submission

- Thorough peer review

- No space constraints or color figure charges

- Immediate publication on acceptance

- Inclusion in PubMed, CAS, Scopus and Google Scholar

- Research which is freely available for redistribution 